\section{Mutation in MMP2 gene may result in scleroderma-like skin thickening}

We read with interest the paper by Banka et $a l^{1}$ who identify microduplications of chromosome $8 \mathrm{q} 22$ as the cause of Leri's pleonostosis, a disease belonging to the 'transforming growth factor beta (TGF-beta)-pathies' group of musculoskeletal disorders. We have been involved in the identification of rare monogenic systemic lupus erythematosus (SLE), especially inherited interferonopathies, ${ }^{2}{ }^{3}$ and we agree with the authors that the common phenotype of autoimmune diseases, such as SLE and systemic sclerosis (SSc), could be explained by involvement of different disease-associated genes in related physiological pathways. Herein we aim to report for the first time that mutation in matrix metalloproteinase-2 (MMP-2) may result in scleroderma-like skin thickening.

A 12-year-old girl was referred because of distal osteoporosis revealed by several pathological appendicular fractures since the age of 8 years. There was no family history. Physical evaluation revealed mildly coarse face, hypertrophic scars and keloids, gum hypertrophy, nodules on the soles, painless contractures of small joints and diffuse skin thickening.

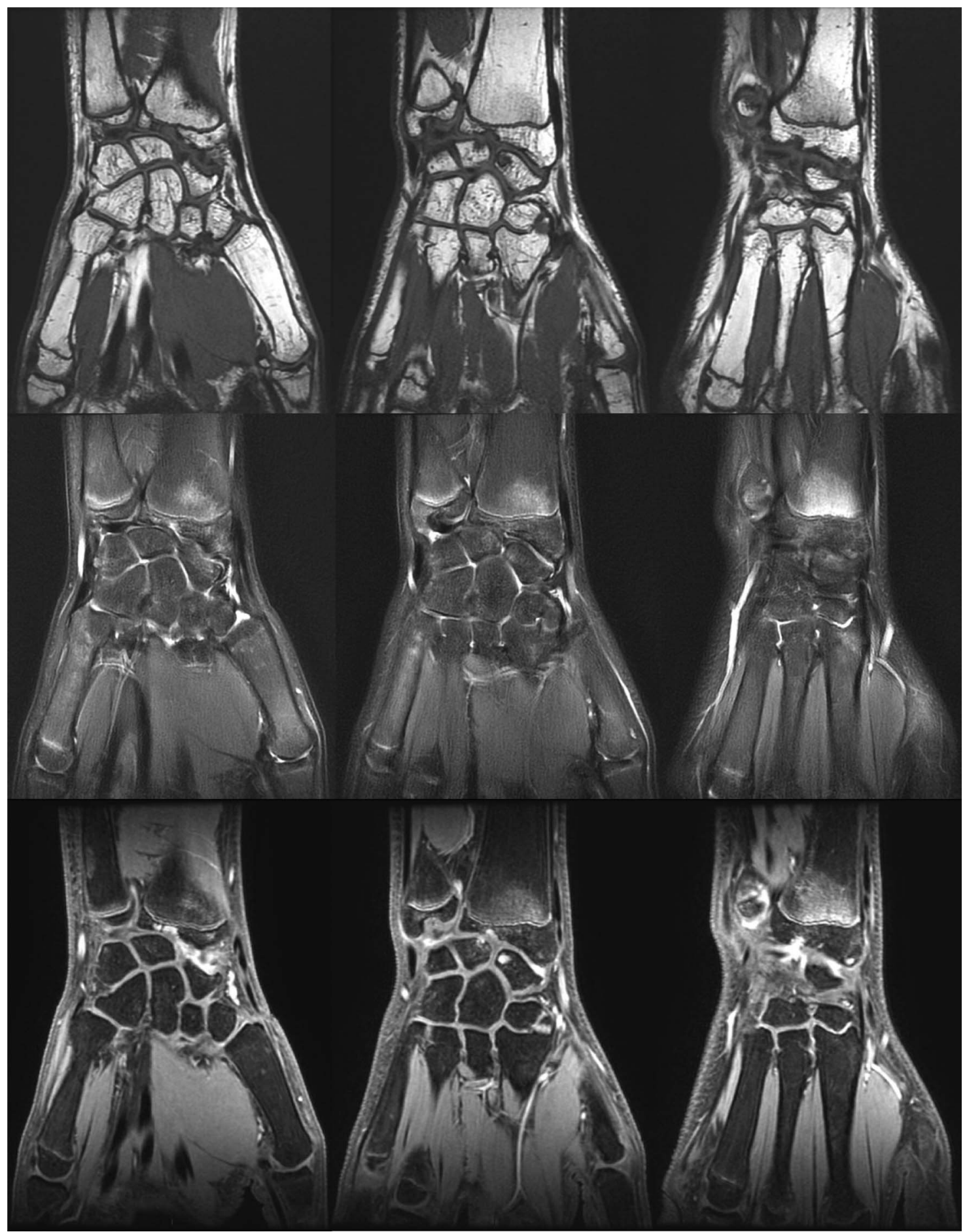

Figure 1 Wrist MRI: small erosive changes of the carpal and proximal metacarpals and enhancement of the synovial were detected. 
Complete blood cell count, erythrocyte sedimentation rate and $\mathrm{C}$ reactive protein level were normal, and antinuclear antibodies and rheumatoid factor were negative. Skeletal survey showed distal osteopenia and carpal osteolysis. Wrist MRI showed multiple small erosive changes in the carpal and proximal metacarpals and enhancement of the synovial was detected (figure 1). According to these clinical and radiological features, the diagnosis of multicentric osteolysis, nodulosis and arthropathy (MONA) syndrome (OMIM \#259600) ${ }^{4} 5$ was considered and confirmed by the presence of two heterozygous missense mutations, c.1188C >A (p.Ser396Arg) and c.1274A >C (p.Tyr425Ser), in the matrix metalloproteinase 2 (MMP2) gene of the patient's DNA. A skin punch biopsy sample was obtained in the same time than the excision of an atypical naevus. It showed a normal epidermis and preserved skin appendages, but extensive fibrosis within the dermis, without any inflammation. At the age of 15 years, the symptoms gradually progressed to involve elbows and knee joints and spine, eventually leading to mobility limitation of the involved joints, and skin thickening worsened.

MONA syndrome belongs to the heterogeneous group of inherited osteolysis syndromes. It is characterised by carpaltarsal destruction, subcutaneous nodules and generalised osteoporosis (multicentric involvement of destruction and resorption). ${ }^{4} 5$ It shows autosomal recessive inheritance and results from protein-inactivating mutation in MMP2, which encodes for a gelatinase and may lead to deregulated enzyme activity. MMP2 specifically cleaves type IV collagen, the major structural component of basement membranes. We report here for the first time that scleroderma-like thickening of skin may be part of the syndrome. Thus, MONA clinical, musculoskeletal and cutaneous manifestations overlap with a number of other conditions, including Leri's pleonostosis, resulting from extracellular matrix (ECM) and TGF-beta signalling abnormalities. ${ }^{1}$

Fibrosis of the skin and internal organs is one of the hallmarks of SSc and corresponds to massive deposits of ECM. ECM can be explained by both increasing expression and deposition of connective tissue protein and decreasing degradation of ECM proteins. Matrix metalloproteases (MMPs), a family of zinc-dependent endopeptidases, are key regulatory molecules in the formation, remodelling and degradation of ECM components. MMP-2, a primary MMP is derived from vascular endothelial cells and smooth muscle cells and degrades various ECM proteins. It has been involved in different fibrotic disorders and its expression, regulation and activity can play an important role in the initial steps of fibrosis. ${ }^{6}$ An imbalance in MMP expression pattern, including a downregulation in MMP2, was demonstrated in the fibroblasts of a patient with subcutaneous fibrotic nodules, severe progressive distal joint contractions and marfanoid stature. ${ }^{7}$ It leads to a disorderly ECM deposition and to a TGF-beta-independent dermal fibrosis.

Conversely, it has been reported that some MMP2 gene polymorphisms do not contribute to the genetic background of SSc in a French European Caucasian population. ${ }^{8}$ However, this study tested only six MMP2 single-nucleotide polymorphisms and did not allow drawing definite conclusion on the implication of MMP2 gene in the pathogenesis of SSc.

Our report suggests that MMP2 mutation could result in a new monogenic scleroderma-like disease. However, additional reports and functional studies are required to confirm this relationship. Such cases of monogenic scleroderma-like diseases have the potential to inform our understanding of pathogenic pathways relevant to the larger SSc population.

\section{B Bader-Meunier, ${ }^{1,2}$ L Bonafé, ${ }^{3}$ S Fraitag, ${ }^{1}$ S Breton, ${ }^{1}$ C Bodemer, ${ }^{1,2}$ G Baujat ${ }^{1,2}$}

${ }^{1}$ Hopital Necker Assistance Publique-Hôpitaux de Paris, France et Imagine Institute, INSERM U1163, Paris, France

${ }^{2}$ Imagine Institute, INSERM U1163, Paris, France

${ }^{3}$ Centre des Maladies Moleculaires (CMM), Centre Hospitalier Universitaire, Vaudois (CHUV), Switzerland

Correspondence to Dr Brigitte Bader-Meunier, 149 rue de Sevres, Paris 75015, France; brigitte.bader-meunier@nck.aphp.fr

Competing interests None declared.

Patient consent Obtained.

Provenance and peer review Not commissioned; internally peer reviewed.

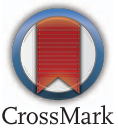

To cite Bader-Meunier B, Bonafé L, Fraitag S, et al. Ann Rheum Dis 2016;75:e1. Accepted 6 September 2015

Published Online First 29 September 2015

\section{Linked}

http://dx.doi.org/10.1136/annrheumdis-2015-208538

Ann Rheum Dis 2016;75:e1. doi:10.1136/annrheumdis-2015-208182

\section{REFERENCES}

1 Banka S, Cain SA, Carim S, et al. Leri's pleonosteosis, a congenital rheumatic disease, results from microduplication at 8q22.1 encompassing GDF6 and SDC2 and provides insight into systemic sclerosis pathogenesis. Ann Rheum Dis 2015;74:1249-56.

2 Crow YJ. Type I interferonopathies: Mendelian type I interferon up-regulation. Curr Opin Immunol 2015:32:7-12.

3 Jeremiah N, Neven B, Gentili M, et al. Inherited STING-activating mutation underlies a familial inflammatory syndrome with lupus-like manifestations. J Clin Invest 2014;124:5516-20.

4 Al-Mayouf SM, Majeed M, Hugosson C, et al. New form of idiopathic osteolysis: nodulosis, arthropathy and osteolysis (NAO) syndrome. Am J Med Genet 2000;93:5-10.

5 Martignetti JA, Aqeel AA, Sewairi WA, et al. Mutation of the matrix metalloproteinase 2 gene (MMP2) causes a multicentric osteolysis and arthritis syndrome. Nature Genet 2001;28:261-5.

6 Droppelmann CA, Gutiérrez J, Vial C, et al. Matrix metalloproteinase-2-deficient fibroblasts exhibit an alteration in the fibrotic response to connective tissue growth factor/CCN2 because of an increase in the levels of endogenous fibronectin. $J$ Biol Chem 2009;284:13551-61.

7 Szauter KM, Ordas A, Laxer RM, et al. A novel fibrotic disorder associated with increased dermal fibroblast proliferation and downregulation of genes of the microfibrillar network. Br J Dermatol 2010;163:1102-15.

8 Wipff J, Dieude P, Avouac J, et al. Association of metalloproteinase gene polymorphisms with systemic sclerosis in the European Caucasian population. J Rheumatol 2010;37:599-602. 